OPEN

SUBJECT AREAS:

CLIMATE-CHANGE

IMPACTS

ENVIRONMENTAL SCIENCES

Received

24 April 2014

Accepted

2 October 2014

Published

24 October 2014

Correspondence and requests for materials should be addressed to N.L. (ningli@bnu.edu. cn) or J.C. (chenjin@ bnu.edu.cn)

* These authors contributed equally to this work.

\section{Earlier vegetation green-up has reduced spring dust storms}

\author{
Bihang Fan ${ }^{1 *}$, Li Guo ${ }^{2 *}$, Ning Li ${ }^{1}$, Jin Chen ${ }^{1,2}$, Henry Lin ${ }^{3}$, Xiaoyang Zhang ${ }^{4}$, Miaogen Shen ${ }^{5,6}$, Yuhan Rao', \\ Cong Wang' \& Lei Ma'
}

'State Key Laboratory of Earth Surface Processes and Resources Ecology, Beijing Normal University, Beijing 100875, China, ${ }^{2}$ College of Global Change and Earth System Science, Beijing Normal University, Beijing 100875, China, ${ }^{3}$ Department of Ecosystem Science and Management, The Pennsylvania State University, University Park, PA 16802, USA, ${ }^{4}$ Geospatial Sciences Centre of Excellence, South Dakota State University, 1021 Medary Ave., Wecota Hall 506B, Brookings, SD 57007, USA, ${ }^{5}$ Key Laboratory of Alpine Ecology and Biodiversity, Institute of Tibetan Plateau Research, Chinese Academy of Sciences, Beijing 100101, China, ${ }^{6}$ CAS Center for Excellence in Tibetan Plateau Earth Sciences, Beijing 100101, China.

The observed decline of spring dust storms in Northeast Asia since the 1950s has been attributed to surface wind stilling. However, spring vegetation growth could also restrain dust storms through accumulating aboveground biomass and increasing surface roughness. To investigate the impacts of vegetation spring growth on dust storms, we examine the relationships between recorded spring dust storm outbreaks and satellite-derived vegetation green-up date in Inner Mongolia, Northern China from 1982 to 2008 . We find a significant dampening effect of advanced vegetation growth on spring dust storms $(r=0.49, p=0.01)$, with a one-day earlier green-up date corresponding to a decrease in annual spring dust storm outbreaks by $3 \%$. Moreover, the higher correlation $(r=0.55, p<0.01)$ between green-up date and dust storm outbreak ratio (the ratio of dust storm outbreaks to times of strong wind events) indicates that such effect is independent of changes in surface wind. Spatially, a negative correlation is detected between areas with advanced green-up dates and regional annual spring dust storms $(r=-0.49, p=0.01)$. This new insight is valuable for understanding dust storms dynamics under the changing climate. Our findings suggest that dust storms in Inner Mongolia will be further mitigated by the projected earlier vegetation green-up in the warming world.

T he spatial and temporal patterns of dust storms are inevitably affected by the changing climate through changes in atmospheric circulation background and near-surface meteorological elements ${ }^{1-4}$ and climatic change-induced variations in ground roughness ${ }^{5-8}$. Linking dust storm dynamics to climatic changes can improve the prediction of dust storm occurrence and its impact on human livehoods under future climate scenarios ${ }^{9-11}$

Northeast Asia (accommodating one fifth of the world population) has been identified as a major dust source region subjected to annual dust storm threats ${ }^{12}$. Distinguished from the increasing trends observed in other major dust storm regions ${ }^{13}$, dust storm outbreak (the number of dust storm occurrences) has been declining since the 1950s in Northeast Asia except for a spike in dust activity in the early $21^{\text {st }}$ century ${ }^{1,4,5,7}$. Apart from the direct effects of climate environment, vegetation response to climatic changes is likely to shape such particular dust storm dynamics in Northeast Asia, where land surface is more extensively covered by vegetation than other major dust storm regions (for example, the Sahel zone and Sahara Desert in North Africa) ${ }^{1,5,7}$.

The impacts of vegetation on dust storms have been preliminarily investigated in a few studies in the spatial domain ${ }^{14-18}$, drawing an agreed conclusion that a greater vigor and amount of vegetation results in fewer dust storms. However, no study has examined the potential effects of vegetation phenology shift on the temporal dynamics of dust storms. Vegetation green-up over the dust storm region in Northeast Asia (mostly grasslands and semi-desert shrubs) usually occurs between late April and early May ${ }^{19-21}$, which happens to synchronize with the dust storm prevailing season there ${ }^{1,7}$. Given that the advanced vegetation green-up brings forward the end of soil exposure period (which reduces surface sediment supply) and the accumulation of aboveground biomass (which increases ground roughness), we thus hypothesize that the earlier green-up should restrain the outbreak of dust storms.

\section{Results}

To test our hypothesis, we examined the correlation and causality between 30-year in situ observations of dust storm outbreaks (with 3,880 dust storm events documented in total) and the satellite-derived vegetation green-up 
dates in Inner Mongolia, Northern China (Method). Over the study period of 1982-2012, 80\% dust storms intensively outbreak in March to May, with the 10-day total dust storm outbreaks peaking in late April (Fig. 1). The inner-annual variations of dust storm outbreaks are well coincident with the variations in strong wind (Fig. 1). From late April to early May (the green shaded period in Fig. 1), dust storm outbreaks dramatically decline from the maximum (59\%), yet only a relatively slight decrease $(22 \%)$ is recorded for strong wind events (measurements when wind speeds at $10 \mathrm{~m}$ above ground are over $9 \mathrm{~m} / \mathrm{s}$; Text S1). If strong wind is the only determinant controlling the occurrence of dust storms, such decline in dust storm outbreaks should be comparable to that in strong wind event. However, the fact is that dust storm reduces much greater than strong wind event does (Fig. 1). This incoordinate decreases in dust storm outbreak and strong wind event implies that the sudden drop in dust storm outbreak may not be driven by surface wind stilling alone, and the rapid vegetation growth after green-up date (also falling between late April and early May over the study area $)^{19-21}$ may suppress the outbreaking of dust storms.

To demonstrate the dampening effect of vegetation spring growth on dust storms, we first compare the decadal variations in annual spring (February to June) dust storm outbreak, annual average spring NDVI, and annual vegetation green-up date (Fig. 2). Over the study period, strong dust storm years (for example, 2001 and 2002) tend to exhibit delayed green-up dates (and lower spring NDVI values), whereas weak dust storm years (for example, 1997 and 1998) are more likely to have earlier green-up dates (and higher spring NDVI values) (Fig. 2).

More specifically, besides of the positive correlation with strong wind event $(r=0.50, p<0.01)$, annual spring dust storm outbreak is significantly related to annual average NDVI $(r=-0.41, p<0.05)$ and regional vegetation green-up date $(r=0.49, p=0.01)$, respectively (Fig. S2). Vegetation green-up date describes $24 \%$ of the year to year variations in spring dust storm outbreak (Fig. S2c). On a regional scale, when vegetation green-up occurs one day earlier, the annual spring dust storm outbreak is reduced by 2.92 times (indicated by the linear regression coefficient of green-up date against spring dust storm outbreak) or 3\% (calculated as 2.92 divided by the multi-year average spring dust storm outbreak).

The binary linear regression shows that vegetation green-up date together with strong wind event explain $47 \%$ of the total year to year variations in spring dust storms (Dust storm outbreak $=0.50 \times$ Strong wind event $+0.49 \times$ Vegetation green-up date; $R^{2}=0.47$, $p<0.01)$. No co-linearity is detected between vegetation green-up date and strong wind event. The comparative regression coefficients of the standardized strong wind event $(0.50)$ and vegetation green-up date (0.49) suggest that the effects from surface wind and vegetation green-up on spring dust storms are approximately much of extent in our study area.

In addition to the regression analysis, we use a newly established causality detection algorithm called convergent cross mapping (CCM; Text S3) $)^{22}$ to test the causation from the shift in vegetation green-up dates to the changes in spring dust storm outbreak. The clear asymmetric CCM suggests a unidirectional causality from vegetation green-up to spring dust storms (Fig. S3a).

To identify the independent contribution of vegetation green-up on restraining spring dust storms, we remove the impacts of surface wind by examining the relationship between annual spring dust storm outbreak ratio and regional vegetation green-up date. Dust storm outbreak ratio calculates the ratio of spring dust storm outbreaks to strong wind events, measuring the probability of outbreaking dust storms $^{23}$ (Text S1). We detect a significant positive correlation between vegetation green-up and dust storm outbreak ratio $(r=0.55, p<0.01)$ (Fig. S2d). A one-day earlier vegetation green-up date leads to a reduction of dust storm outbreak ratio by $0.41 \%$ (with the average dust storm outbreak ratio of $15.98 \%$ over the study area). Therefore, the restraining effect of vegetation green-up on springtime dust storms is robust to the changes in surface wind.

Comparison of the annual anomalies shows that $70 \%$ of the study years ( 18 out of 27 years) exhibit the same trend (above or under the multi-year average) in both dust storm outbreak ratio and vegetation green-up date (Fig. 3a). Zooming to the two-month period around vegetation green-up date, no temporal trend in daily average dust storm outbreak ratio is detected before green-up date; whereas after green-up date, dust storm outbreak ratio significantly goes downward $(-0.34 \% /$ day, $p<0.01)$, decreasing over a half within a month thereafter (Fig. $3 \mathrm{~b}$ and c). Causality detection further demonstrates the physical connection from green-up date shift to spring dust storm outbreak ratio (Fig. S3b).

Spatial patterns of green-up date anomalies also suggest a strong correspondence between vegetation green-up and spring dust storms (Fig. 4 and S4). Based on the average annual spring dust storm

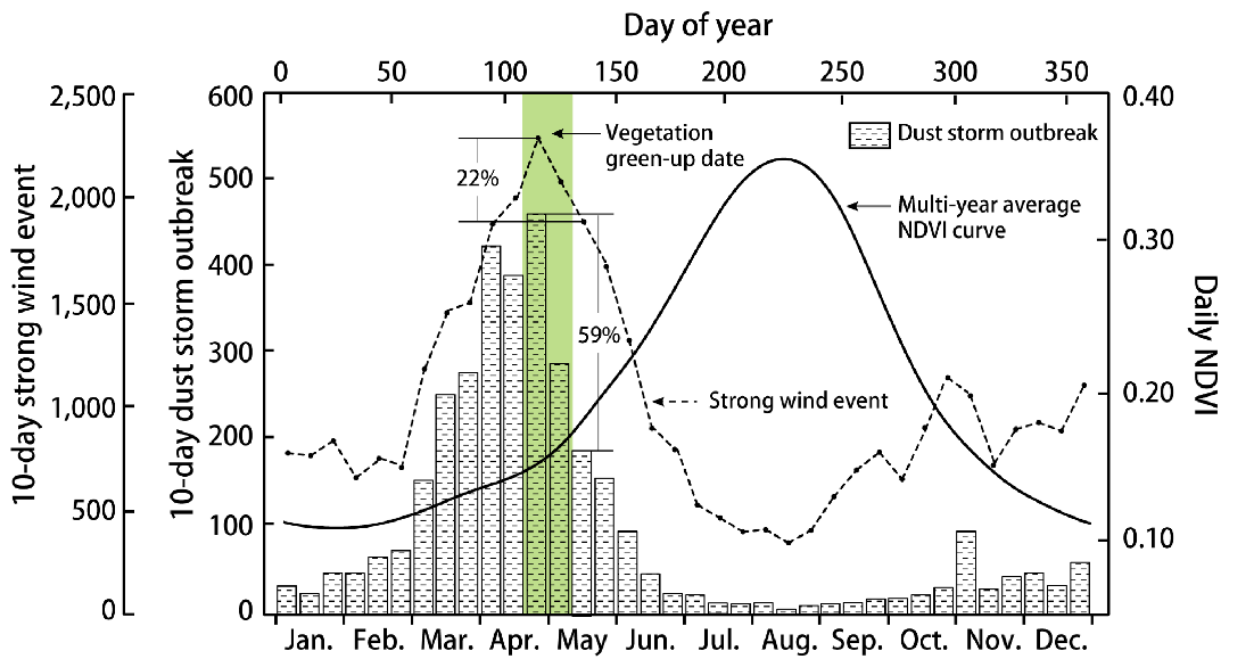

Figure 1 Incoordinate decreases in dust storm outbreak and strong wind event after vegetation green-up date. Histograms and dashed line indicate regional multi-year averaged 10-day dust storm outbreak and strong wind event over the 1982-2012 period in Inner Mongolia, Northern China $\left(37.61^{\circ}-46.78^{\circ} \mathrm{N}, 105.24^{\circ}-119.89^{\circ} \mathrm{E}\right)$. Solid line is the regional daily NDVI averaged from 1982 to 2008 . Green shade indicates the approximate vegetation green-up date over the study area. After vegetation green-up (from late April to early May), the declines in strong wind event and dust storm outbreak are $22 \%$ and $59 \%$, respectively. Clearly, dust storm reduces much greater than strong wind event does during this relatively short period. 


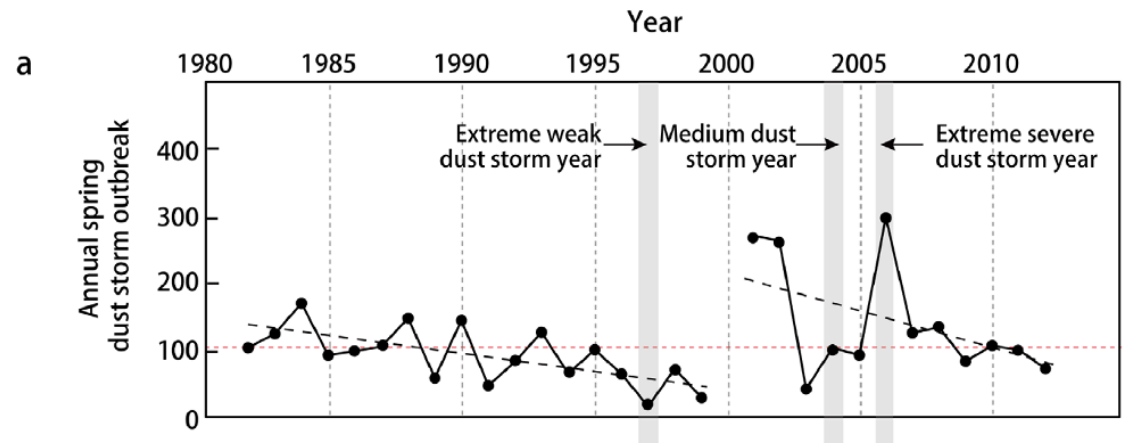

b

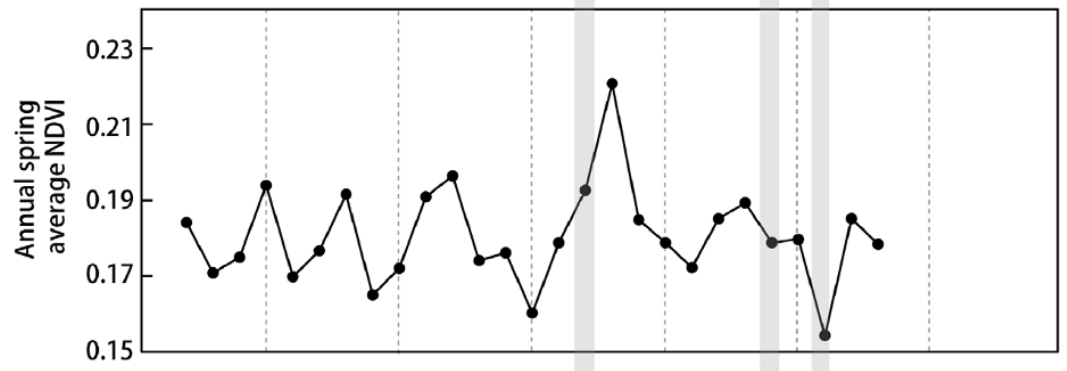

c

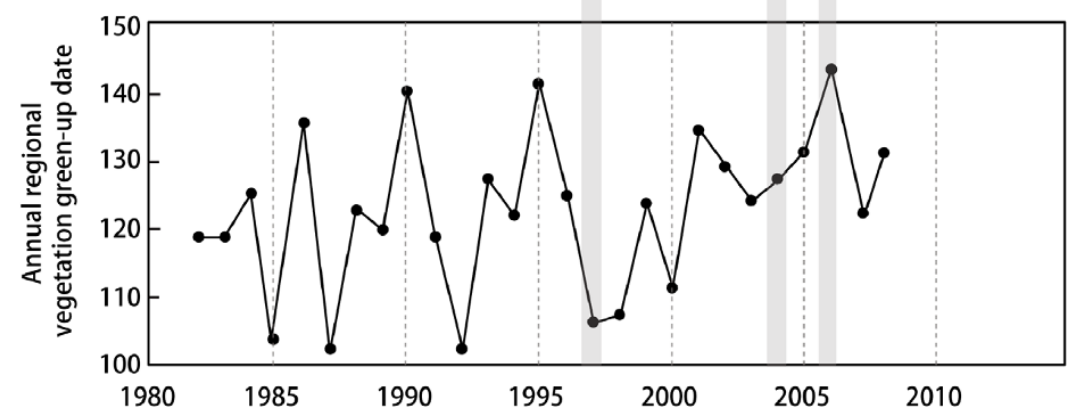

Figure $2 \mid$ The restraining effect of vegetation condition on spring dust storm outbreak. (a), (b), (c), Decadal variations in regional spring (February to June) dust storm outbreak, average NDVI, and vegetation green-up date. Red dashed line indicates the multi-year averaged spring dust storm outbreak. Black dashed lines indicate the significant decline trends detected in spring dust storm outbreak from 1982 to 1999 and from 2001 to 2012 . Vertical dashed lines show 5-year intervals. Grey shades indicate the selected extreme weak (1997), the medium (2004), and the extreme severe dust storm year (2006).

outbreak (the red dashed line on Fig. 2a), one representative year is selected for each of the following, the extreme weak (1997), the medium (2004), and the extreme severe dust storm year (2006). Correspondingly, $73 \%, 42 \%$, and $18 \%$ of the study area, respectively, shows an advanced green-up date in each of the three years (Fig. 4). A significant negative correlation is unveiled between the areas with earlier green-up dates and the regional annual spring dust storm outbreak $(r=-0.49, p=0.01)$ over the whole study period (Fig. S4). Namely, a $10 \%$ increase in areas with an earlier green-up date leads to a reduction in the regional annual spring dust storm outbreak by 17 times (or 16\%, calculated as 17 divided by the regional multi-year average spring dust storm outbreak). An ANOVA indicates a significant difference of areas with earlier green-up dates between the weak dust storm years and the strong dust storm years (Fig. S4).

\section{Discussion}

In Northeast Asia, the restraining effect of vegetation growth (measured by growing season average Normalized Difference Vegetation Index, NDVI) on dust storm outbreaks has been previously reported ${ }^{4}$. However, temporally, growing season average NDVI (primarily determined by vegetation status in summertime, June to August) fails to match the dust storm prevailing season (March to May) $)^{1,3,7}$ in Northeast Asia. Thus, using growing season NDVI cannot accurately capture the dampening effect from spring vegetation condition on dust storms. Different with previous studies, we employ vegetation green-up date as an indicator to study the dynamics of dust storm caused by spring vegetation growth. Green-up date indicates the end of soil exposure period and the start of aboveground biomass rapid accumulation ${ }^{19}$, and is therefore more effective to reflect the vegetation condition in dust storm season. Our result supports that green-up date is even better than spring average NDVI to characterize the restraining effect of vegetation on spring dust storms (Fig. S2). More importantly, adopting green-up date instead of NDVI expands our knowledge of vegetation's impact on dust storm from the spatial domain to the temporal domain. Findings in this study suggest that amount (indicated by NDVI) and phenology (indicated by green-up date) of vegetation both affect dust activity (Fig. S2).

Among different determinants, such as wind velocity, surface sediment supply, and ground roughness ${ }^{5,24-26}$, vegetation condition is just one factor influencing dust storms. The variations in hydrothermal conditions are the ultimate forces shaping the dynamics of dust storm $^{5}$. However, the relationship between hydrothermal conditions and dust storm is not simply linear. For example, higher temperature can boost vegetation growth, leading to greater vegetation coverages ${ }^{27}$ and lower surface wind speeds. In this case, the increased temperature suppresses dust storms. Nevertheless, higher temperature without accompanied increased precipitation will induce drought ${ }^{28}$ and enhance surface sediment supply. Thus, higher temperature facilitates dust storm outbreaks. No wonder in previous studies ${ }^{1,6}$, no significant correlation was found between spring temperature (or precipitation) and spring dust storms. Vegetation green-up is an integrated indicator of hydrothermal conditions ${ }^{21}$. The suitable condition for vegetation 
a

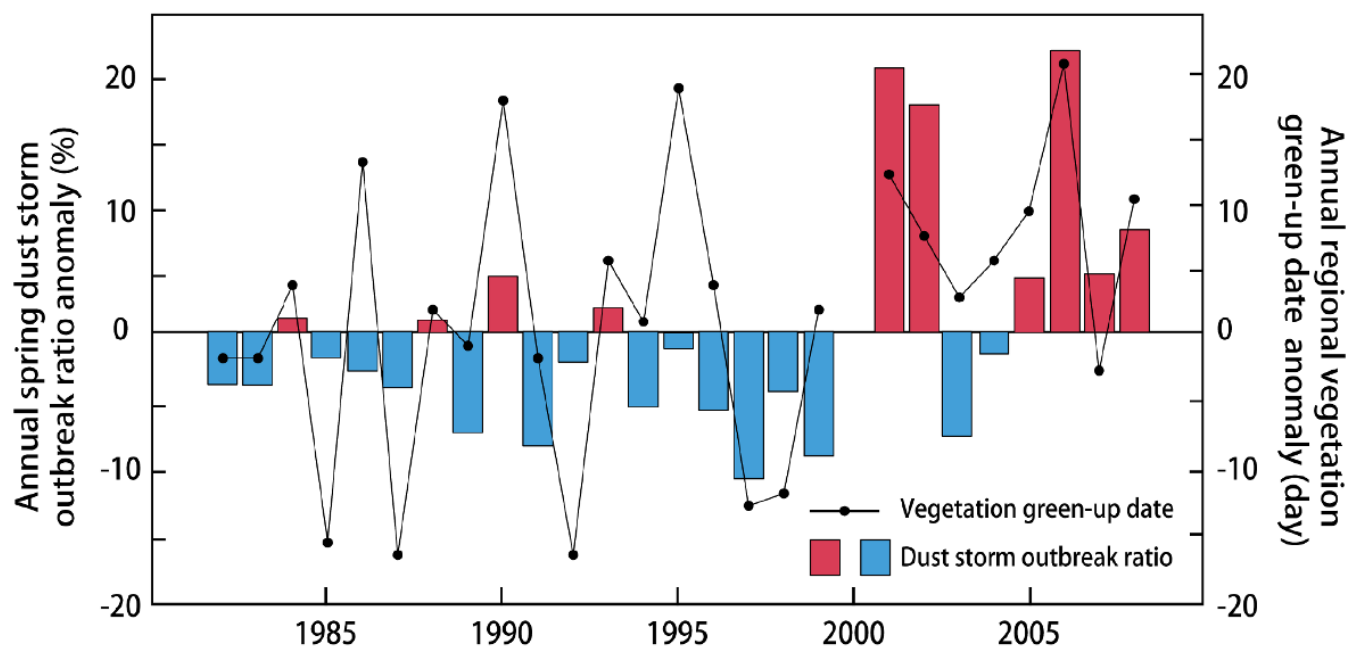

b

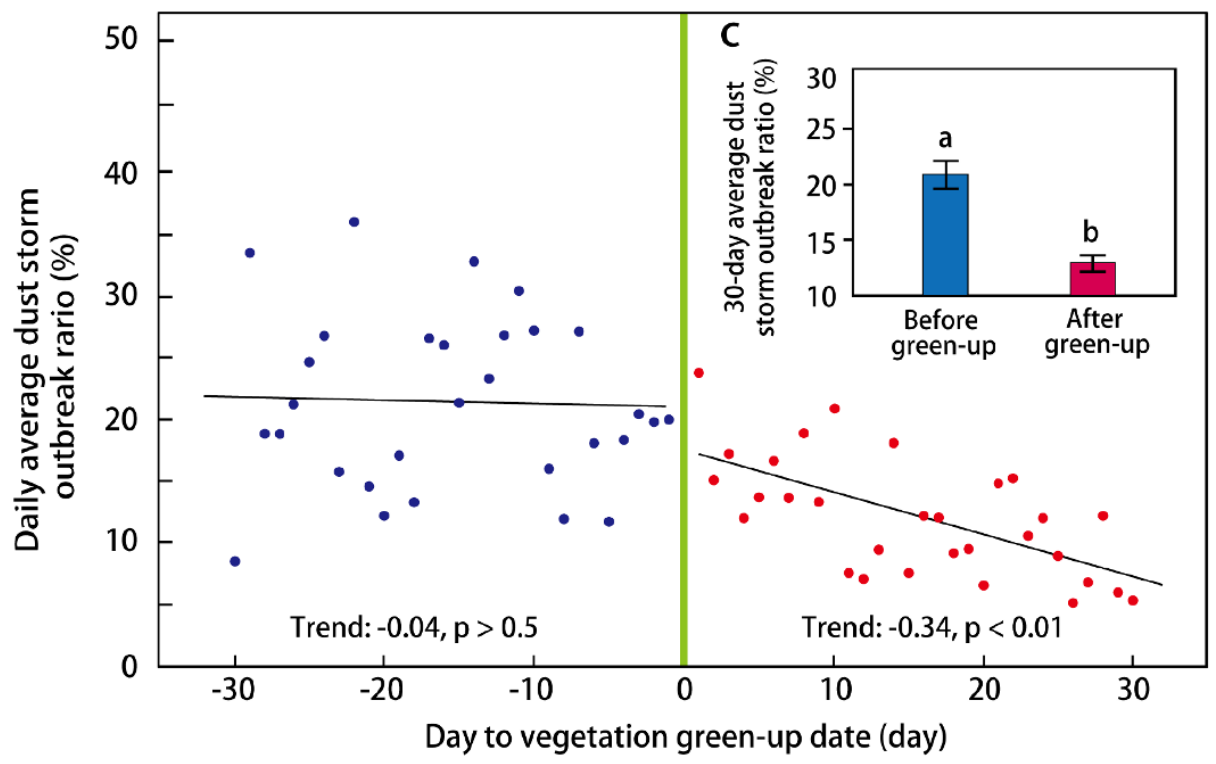

Figure 3 Vegetation green-up suppresses dust storm outbreak ratio. (a), Regional decadal anomalies of annual spring dust storm outbreak ratio (the ratio of spring dust storm outbreaks to strong wind events, indicated by histograms) and vegetation green-up date (dots) over the study area from 1982 to 2008. (b), Trends of 26-year averaged daily dust storm outbreak ratio before (blue dots) and after green-up date (red dots). A significant decline trend of average daily dust storm outbreak ratio is observed after green-up date. (c), 30-day multi-year averaged daily dust storm outbreak ratio before and after vegetation green-up date. Error bars represent one standard error. Different lowercase letters above the bars indicate a significant difference between the average 30-day average dust storm outbreak ratio before and after vegetation green-up date $(p<0.05)$.

green-up (a warm spring with moderate precipitation) ${ }^{29,30}$ is just the adverse condition for outbreaking dust storms ${ }^{1,2,7}$. Unlike the nonlinear relationship between dust storm and hydrothermal conditions, we successfully establish a linear correlation between vegetation greenup date and spring dust storm outbreaks (Fig. S2). Therefore, vegetation green-up, a result of the balance between the overall hydrothermal conditions, can show such a significant effect on dust storm outbreaks (Figs. 4 and S4).

Apart from the indication of environment conditions, the physical mechanisms leading to reduced dust storms after vegetation greenup and fewer spring dust storms in years with earlier green-up dates can be explained as: (1) After green-up, vegetation rapidly grows, accumulating aboveground biomass and forming a more complex canopy structure ${ }^{31,32}$. A wind slowdown area appears behind plants and declines the velocity of surface friction wind ${ }^{33}$. In the meantime, the larger vegetation coverage after green-up increases the surface roughness, raising the threshold wind speed needed for triggering a dust storm. Therefore, spring dust storms are suppressed after vegetation green-up (Figs. 1 and 3); and (2) an earlier vegetation green-up brings forward the end of soil exposure period and thus reduces surface sediment supply. Even when considering the duration of the soil surface is exposed remains unchanged with the earlier green-up (by assuming that the end of surface thawing would also advance as temperature warms), the earlier soil exposure period corresponds to a stage with less strong wind events (Fig. 1), thus resulting in a decrease in spring dust storms. If the shortening of soil exposure period due to earlier green-up can be considered ${ }^{34,35}$, the restraining effect of earlier vegetation growth on spring dust storms will be more significant.

The observed dampening effect of vegetation green-up on dust storm outbreaks is probably site-specific, relying on the local vegetation coverage. In our study area, land surface is extensively covered by grasses and shrubs (Fig. S1). Hence, vegetation green-up can play a significant role in restraining spring dust storm outbreaks. Whereas for other dust source regions with limited vegetation coverage, such as Taklimakan Desert, the effect of vegetation green-up on dust storm dynamics is not this significant ${ }^{14}$.

Recently, besides of the natural factors, human activities also affect the dynamics of dust storm via changing vegetation coverage and direct dust emissions ${ }^{36-39}$. Over grazing and disafforestation have 
a

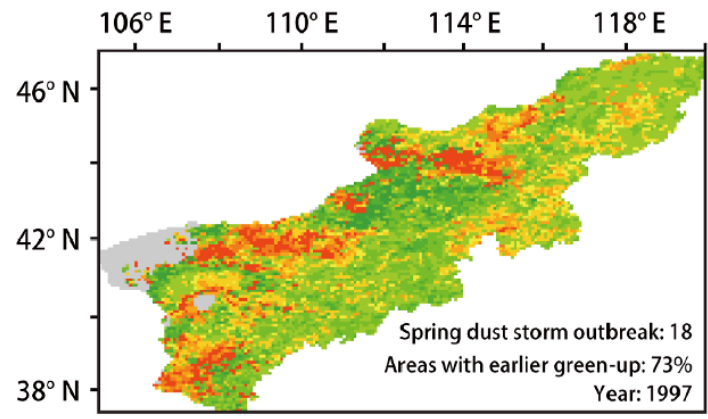

b

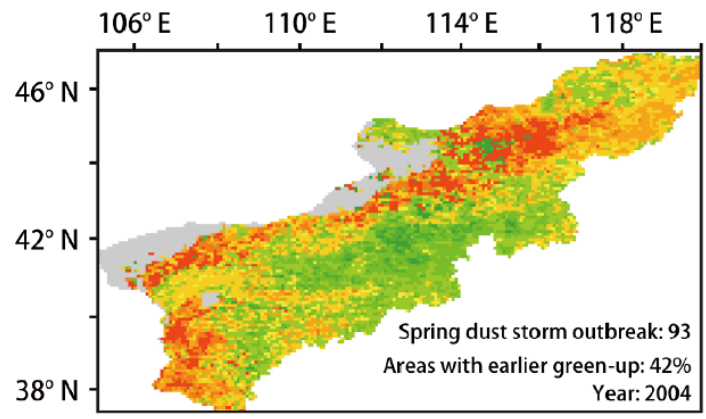

C

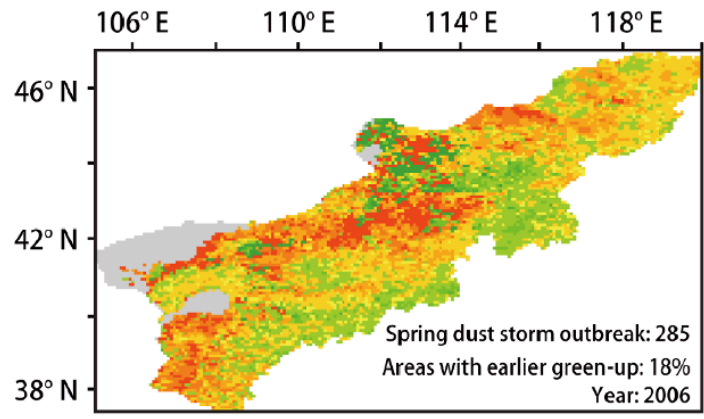

$\begin{array}{lllllllll}-30 & -20 & -10 & -1 & 1 & 10 & 20 & 30 & \text { Bare land }\end{array}$

$\Delta$ Vegetation green-up date (day)

Figure $4 \mid$ The correspondence between pixel scale $\left(8 \times 8 \mathrm{~km}^{2}\right)$ green-up date anomalies ( $\Delta$ vegetation green-up date) and regional spring dust storm outbreaks. (a), Extreme weak dust storm year (1997). (b), Medium dust storm year (2004). c, Extreme severe dust storm year (2006). Listing the percentage of study area with an earlier vegetation green-up date (green areas) and spring dust storm outbreaks in each of the three study years. Method used for pixel scale vegetation green-up date extraction is presented in Text S2. The Figure was drawn using ArcGIS 10 and ENVI 5.0.

reduced the vegetation coverage in Inner Mongolia ${ }^{40}$. Fortunately, the Chinese government is taking measures to restore overgrazed land to natural grasslands in Inner Mongolia ${ }^{40}$. If the vegetation coverage keeps recovering, the expected earlier vegetation green-up due to global warming ${ }^{28,41,42}$ will further mitigate spring dust storms in this region.

In summary, this study validates and evaluates the significant effects of vegetation green-up shift on spring dust storms in Inner Mongolia. Our results indicate that (1) vegetation green-up date is more appropriate than spring NDVI in characterizing the effects of spring vegetation growth on spring dust storm outbreaks; (2) vegetation green-up has comparable effects on spring dust storms as surface wind, and vegetation green-up date together with strong wind event can describe half of the variations in spring dust storms; (3) after removing the effect of strong wind, the probability of dust storm outbreak (indicated by dust storm outbreak ratio) decreases continuously after green-up date, indicating an independent restraining effect of vegetation green-up on spring dust storms; and (4) the number of regional spring dust storms tends to be suppressed when more areas have earlier vegetation green-up dates. This study is the first to look at dust storm variations caused by vegetation phenology, which supplements the impact of vegetation on dust storm dynamics. Findings in this study provide a new line of evidence to understand dust storm variations under the changing climate. This new insight may be applied to explain the decline in dust storm activity over other dust storm regions such as the arid and semi-arid areas in central North America ${ }^{5}$, where, similar to Inner Mongolia, land surface is covered with grasses and shrubs, and vegetation could exert a crucial impact on dust storm dynamics.

\section{Methods}

In situ meteorological observation datasets (including current weather condition, surface wind speed measured at $10 \mathrm{~m}$ above ground, and visibility) of 23 meteorological stations in Inner Mongolia, Northern China (a major dust source region in Northeast Asia; Fig. S1) were downloaded from the World Surface Data, which is maintained by China Meteorological Data Sharing Service System (http://cdc.cma. gov.cn), over the period of 1982-2012. Basic information of the selected meteorological stations is presented in Table S1. Definitions of meteorological indices are specified in Text S1 and Tables S2.

NDVI time series used in this study are from the Global Inventory Monitoring and Modeling studies (GIMMS) database obtained by the Advanced Very High Resolution Radiometer (AVHRR) remote-sensed observations ${ }^{43}$, and they cover a 27year period (1982-2008) and have been carefully calibrated (Text S2). The original GIMMS NDVI was produced at a spatial resolution of $8 \times 8 \mathrm{~km}^{2}$ and was composited using the 15-day maximum-value. Vegetation green-up date is derived from the annual NDVI time series using a relative change rate method ${ }^{41,43}$. Detailed procedures of deriving the green-up date from NDVI time series are presented in Text S2.The statistical analyses used in this study, including correlation analysis, unitary and binary linear regression, and one-way ANOVA, are all processed in SPSS for Windows 16.0 (SPSS Inc., USA). Causality detection is based on the convergent cross mapping (CCM) method developed by Sugihara et al..$^{22}$, which can be used to distinguish causality between variables with synergistic effects (Text S3).

1. Qian, W., Quan, L. \& Shi, S. Variations the dust storms in China and its climatic control. J. Clim. 15, 1216-1229 (2002).

2. Ding, R. Q., Li, J. P., Wang, S. G. \& Ren, F. M. Decadal change of the spring dust storm in northwest China and the associated atmospheric circulation. Geophys. Res. Lett. 32, L02808 (2005).

3. Kurosaki, Y. \& Mikami, M. Recent frequent dust events and their relation to surface wind in East Asia. Geophys. Res. Lett. 30, 1736 (2003).

4. Lee, E. H. \& Sohn, B. J. Recent increasing trend in dust frequency over Mongolia and Inner Mongolia regions and its association with climate and surface condition change. Atmos. Environ. 45, 4611-4616 (2011).

5. Goudie, A. S. Dust storms: Recent developments. J. Environ. Manage. 90, 89-94 (2009).

6. Zou, X. K. \& Zhai, P. M. Relationship between vegetation coverage and spring dust storms over northern China. J. Geophys. Res. 109, D03104 (2004).

7. Wang, X., Dong, Z., Zhang, J. \& Liu, L. Modern dust storms in China: an overview. J. Arid Environ. 58, 559-574 (2004).

8. Park, H. S. \& Sohn, B. J. Recent trends in changes of vegetation over East Asia coupled with temperature and rainfall variations. J. Geophys. Res. 115, D14101 (2010).

9. Schlesinger, W. H. et al. Biological feedback in global desertification. Science 247, 1043-1048 (1990).

10. Toon, O. B. Atmospheric science: African dust in Florida Clouds. Nature 424, 623-624 (2003).

11. Creamean, J. M. et al. Dust and biological aerosols from the Sahara and Asia influence precipitation in the Western U.S. Science 339, 1572-1578 (2013).

12. Goudie, A. S. \& Middleton, N. J. The changing frequency of dust storms through time. Climatic Change 20, 197-225 (1992).

13. Moulin, C., Lambert, C. E., Dulac, F. \& Dayan, U. Control of atmospheric export of dust from North Africa by the North Atlantic Oscillation. Nature 387, 691-694 (1997).

14. Lee, E. H. \& Sohn, B. J. Examining the impact of wind and surface vegetation on the Asian dust occurrence over three classified source regions. J. Geophys. Res. 114, D06205 (2009).

15. Lee, J. J. \& Kim, C. H. Roles of surface wind, NDVI and snow cover in the recent changes in Asian dust storm occurrence frequency. Atmos. Environ. 59, 366-375 (2012).

16. Kimura, R. Factors contributing to dust storms in source regions producing the yellow-sand phenomena observed in Japan from 1993 to 2002. J. Arid Environ. 80, 40-44 (2012). 
17. Engelstaedter, S., Kohfeld, K. E., Tegen, I. \& Harrison, S. P. Controls of dust emissions by vegetation and topographic depressions: An evaluation using dust storm frequency data. Geophys. Res. Lett. 30, 1294 (2003).

18. Sun, J., Zhang, M. \& Liu, T. Spatial and temporal characteristics of dust storms in China and its surrounding regions, 1960-1999: relations to source area and climate. J. Geophys. Res. 106, 10325-10333 (2001).

19. Cong, N. et al. Spring vegetation green-up date in China inferred from SPOT NDVI data: A multiple model analysis. Agr. Forest Meteorol. 165, 104-113 (2012).

20. Cong, N. et al. Changes in satellite-derived spring vegetation green-up date and its linage to climate in China from 1982 to 2010: a multimethod analysis. Glob. Change Boil. 19, 881-891 (2013).

21. Liu, H., Tian, F., Hu, H. C., Hu, H. P. \& Sivapalan, M. Soil moisture controls on patterns of grass green-up in Inner Mongolia: an index based approach. Hydrol. Earth Sys. Sci. 17, 805-815 (2013).

22. Sugihara, G. et al. Detecting causality in complex ecosystems. Science $\mathbf{3 3 8}$ 496-500 (2012).

23. Kimura, R., Bai, L. \& Wang, J. Relationships among dust outbreaks, vegetation cover, and surface soil water content on the Loess Plateau of China, 1999-2000. Catena 77, 292-296 (2009).

24. Kok, J. F., Parteli, E. J., Michaels, T. I. \& Karam, D. B. The physics of wind-blown sand and dust. Rep. Prog. Phys. 75, 106901 (2012).

25. Li, N., Gu, W., Du, Z. X., Li, Z. J. \& Song, P. G. Observation on Soil Water Content and Wind Speed in Erlianhot, a dust-source area in northern China. Atmos. Environ. 40, 5298-5303 (2006).

26. Li, N., Gu, W., Levy, J. K. \& Okada, N. The utility of Hayashi's quantification theory for assessment of land surface indices in influence dust storm: a case study in Inner Mongolia China. Atmos. Environ. 39, 119-126 (2005).

27. Zhou, L. M. et al. Variations in northern vegetation activity inferred from satellite data of vegetation index during 1981 to 1999. J. Geophys. Res. 106, D17 (2001).

28. Barber, V. A., Juday, G. P. \& Finney, B. P. Reduced growth of Alaska white spruce in the twentieth century from temperature-induced drought stress. Nature 405, 668-672 (2000).

29. Yu, F., Prince, K. P., Ellis, J. \& Shi, P. Response of seasonal vegetation development to climatic variations in eastern central Asia. Remote Sens. Environ. 87, 42-54 (2003).

30. Badeck, F. W. et al. Responses of spring phenology to climate change. New Phytol. 162, 295-309 (2004).

31. Bazzaz, F. A. The physiological ecology of plant succession. Ann. Rev. Ecol. Syst. 10, 351-371 (1979).

32. Zhang, X. et al. Monitoring vegetation phenology using MODIS. Remote Sens. Environ. 84, 471-475 (2003).

33. Goudie, A. S. \& Middleton, N. J. Saharan dust storms: nature and consequences. Earth-Science Rev. 56, 179-204 (2001).

34. Zhang, X., Freidl, M. A., Schaaf, C. B. \& Strahler, A. H. Climate controls on vegetation phonological patterns in northern mid-and high latitudes inferred from MODIS data. Glob. Change Biol. 10, 1133-1145 (2004).

35. Piao, S., Fang, J., Zhou, L., Ciais, P. \& Zhu, B. Variations in satellite-derived phenology in China's temperate vegetation. Glob. Change Biol. 12, 672-685 (2006).

36. Li, G., Chen, J., Ji, J., Yang, J. \& Conway, T. M. Natural and anthropogenic sources of East Asian dust. Geology 37, 727-730 (2009).
37. Takemura, T., Uno, I., Nakajima, T., Higurashi, A. \& Sano, I. Modeling study of long-range transport of Asian dust and anthropogenic aerosols from East Asia. Geophys. Res. Lett. 29, 2158 (2002).

38. Gong, S. L., Zhang, X. Y., Zhao, T. L. \& Barrie, L. A. Sensitivity of Asian dust storm to natural and anthropogenic factors. Geophys. Res. Lett. 31, L07201 (2004).

39. Igarashi, Y. et al. Possible change in Asian dust source suggested by atmospheric anthropogenic radionuclides during the 2000s. Atmos. Environ. 43, 2971-2980 (2009).

40. Han, J. G. et al. Rangeland degradation and restoration management in China. Rangeland J. 30, 233-239 (2008).

41. Piao, S. et al. Altitude and temperature dependence of change in the spring vegetation green-up date from 1982 to 2006 in the Qinghai-Xizang Plateau. Agr. Forest Meteorol. 151, 1599-1608 (2011).

42. Jeong, S. J., Ho, C. H., Gim, H. J. \& Brown, M. E. Phenology shifts at start vs. end of growing season in temperate vegetation over the Northern Hemisphere for the period 1982-2008. Global Change Biol. 17, 2385-2399 (2011).

43. Tucker, C. J. et al. An extended AVHRR 8-km NDVI data set compatible with MODIS and SPOT vegetation NDVI data. Int. J. Remote Sens. 26, 4485-4498 (2005).

\section{Acknowledgments}

This study was jointly supported by the National Basic Research Program of China (Grant No. 2012CB955501) and the National Natural Science Foundation of China (Grant No. 41171401), the National Basic Research Program of China (Grant No. 2012CB955402), the National Natural Science Foundation of China (Grant No. 41201459).

\section{Author contributions}

J.C. and N.L. conceived and designed the study. L.G. and B.F. conducted the statistical analysis and wrote the manuscript with feedback from other authors. L.M. and C.W. derived vegetation green-up dates from the NDVI time series. Y.R. performed the causality detection analysis. H.L., X.Z. and M.S. contributed to refining the manuscript. All authors contributed to discussion and gave comments on the manuscript.

\section{Additional information}

Supplementary information accompanies this paper at http://www.nature.com/ scientificreports

Competing financial interests: The authors declare no competing financial interests. How to cite this article: Fan, B. et al. Earlier vegetation green-up has reduced spring dust storms. Sci. Rep. 4, 6749; DOI:10.1038/srep06749 (2014).

This work is licensed under a Creative Commons Attribution-NonCommercialNoDerivs 4.0 International License. The images or other third party material in this article are included in the article's Creative Commons license, unless indicated otherwise in the credit line; if the material is not included under the Creative Commons license, users will need to obtain permission from the license holder in order to reproduce the material. To view a copy of this license, visit http:// creativecommons.org/licenses/by-nc-nd/4.0/ 